\title{
WAHANA EDUKASI DAN KEMANDIRIAN PANGAN DENGAN BIOKONVERSI SAMPAH ORGANIK RUMAH TANGGA
}

\author{
Nur Chabibah ${ }^{1 *}$, Rini Kristiyanti², Anis Sofiana ${ }^{3}$, Milatun Khanifah ${ }^{4}$ \\ 1,2,4, Jurusan Diploma III Kebidanan/Fakultas Kesehatan, Universitas Muhammadiyah Pekajangan Pekalongan \\ ${ }^{3}$ Fakultas Pertanian, Universitas Muhammadiyah Purwokerto \\ *Email: nchabibah@ymail.com
}

\begin{abstract}
Abstrak
Sampah merupakan masalah lingkungan yang dihadapi oleh semua pemukiman. Kendala pengelolaan sampah seperti kesulitan lahan tempat pemprosesan akhir, terbatasnya armada pengangkut, kurangnya kesadaran masyarakat untuk mengelola sampah sejak dari sumbernya, teknologi pengolahan sampah juga masih tradisional, hingga kendala minimnya sumber daya manusia mengenai penanganan sampah. Selain itu, pengelolaan sampah membutuhkan biaya yang tidak sedikit. Masyarakat perlu dukungan teknologi serta informasi yang cukup agar dapat berpartisipasi dalam pengelolaan sampah. Tujuan kegiatan ini adalah mengajak serta masyarakat dalam pengolahan sampah organik rumah tangga sehingga dapat mengangkat nilai ekonomi maupun kemandirian pangan. Metode yang dilakukan antara lain edukasi pilah sampah, pelatihan teknik pengolahan sampah organik rumah tangga menggunakan metode biokonversi dan pemanfaatan produk samping pengolahan sampah, pembuatan instalasi dan pengoperasian pengolahan sampah organik rumah tangga, pemanfaatan produk samping pengolahan sampah organik rumah tangga berupa pupuk organik dan bahan substitusi pakan ternak, evaluasi pelaksanaan kegiatan dan pembuatan rencana tindak lanjut untuk pengembangan lingkungan dan pengembangan mikro usaha. Luaran pengabdian masyarakat berupa peningkatan pengetahuan pilah sampah dan keterampilan warga dalam memanfaatkan sampah organik rumah tangga maupun hasil residu sampah sebagai pupuk organik dan bahan pakan ternak sehingga dapat membantu kemandirian pangan ditingkat rumah tangga.
\end{abstract}

Kata Kunci : biokonversi, sampah organik, wahana edukasi, kemandirian pangan

\begin{abstract}
Waste is an environmental problem faced by all settlements. Garbage management constraints such as the difficulty of land where the final processing, the limited fleet of transporters, the lack of public awareness to manage waste from the source, the technology of garbage management is still traditional, to the constraints of the lack of human resources regarding garbage management. In addition, garbage management requires not a small amount of money. The community needs sufficient technology and information support to be able to participate in garbage management. The purpose of this activity is to invite the community to process household organic garbage so that it can lift economic value and food independence. The methods that were carried out included education of garbage sorting, training on household organic garbage processing techniques using the bioconversion method and utilization of waste management byproducts, making installations and operations for processing household organic waste, utilizing the by-products of processing household organic garbage in the form of organic
\end{abstract}

$$
\text { Kesehatan } 444
$$


fertilizers and substitutes animal feed, evaluating the implementation of activities and making followup plans for environmental development and micro business development. The level of community service in the form of increasing knowledge of garbage sorting and the skills of residents in utilizing household organic garbage as well as the results of garbage residues as organic fertilizer and animal feed ingredients so that it can help food independence at the household level.

Keywords: bioconversion, organic garbage, educational vehicle, food independence

\section{PENDAHULUAN}

Data dari KNLH pada tahun 2010 menyebutkan volume sampah naik dua kali lipat yakni mencapai $200 \mathrm{ribu}$ ton/hari dan diprediksi pada tahun 2020 volume sampah di Indonesia akan meningkat lima kali lipat dibanding pada tahun 2010. Artinya Indonesia akan memproduksi satu juta ton tumpukan sampah per hari. ${ }^{1}$ Penyumbang volume sampah terbesar pada komposisi sampah adalah sampah dapur dan sampah halaman yang masuk dalam kategori sampah organik. Dimana seharusnya sampah tersebut dapat dimanfaatkan apabila masyarakat mempunyai kemampuan dan keinginan untuk dapat mengelola sampah secara bijak.

Pengelolaan sampah telah diatur pemerintah melalui Undang-undang Nomor 18 Tahun 2008 mengenai Pengelolaan Sampah. Undang-undang tersebut mengatur bahwa pengelolaan sampah tidak hanya menjadi kewajiban pemerintah saja. Masyarakat dan perilaku usaha sebagai penghasil sampah juga bertanggung jawab menciptakan lingkungan yang bersih dan sehat. Pemerintah melalui Undang-undang tersebut memberi ruang yang cukup banyak bagi pemerintah daerah untuk merencanakan dan mengolah sampah di kawasannya. ${ }^{2}$

Implementasi peraturan daerah Kabupaten Pekalongan Nomor 4 tahun 2017 tentang Pengelolaan Sampah dengan mempromosikan program pengolahan sampah secara terpadu berbasis masyarakat untuk mereduksi sampah semaksimal mungkin melalui pengolahan sampah di lokasi terdekat dengan sumber sampah. Pemerintah daerah juga meluncurkan beragam program pembangunan fisik, seperti: Tempat Pengelolaan
Sampah Terpadu, pendirian bank sampah, dan pembentukan Kampung Ramah Lingkungan. ${ }^{3}$

Namun demikian program tersebut tidak berjalan maksimal, belum banyak warga yang berpartisipasi dalam mengolah dan memanfaatkan sampah. Kondisi tersebut diperparah dengan kendala seperti kesulitan penyediaan lahan Tempat Pemprosesan Akhir (TPA), terbatasnya armada pengangkut, kurangnya kesadaran masyarakat untuk mengelola sampah sejak dari sumbernya, teknologi pengolahan sampah juga masih tradisional, hingga kendala minimnya Sumber Daya Manusia (SDM) mengenai penanganan sampah, serta biaya dalam membangun sarana dan fasilitas pengelolaan sampah yang tidak sedikit.

Kendala pengelolaan sampah juga terjadi di Perumahan Villa Pisma Asri Kabupaten Pekalongan dimana terdapat fasilitas umum berupa Tempat Penampungan Sementara (TPS) yang telah disediakan oleh pengembang perumahan justru belum dimanfaatkan secara optimal karena terdapat penolakan oleh beberapa warga sekitar lokasi akibat kekhawatiran terkait pencemaran kualitas udara dan pengetahuan warga yang kurang dalam pengelolaan sampah ramah lingkungan. Kondisi tersebut justru menciptakan permasalahan baru, sehingga dalam kesempatan forum diskusi warga di lingkungan RT 06 RW 05 Perumahan Villa Pisma Asri Kabupaten Pekalongan merasa perlu melakukan revitalisasi Tempat Penampungan Sementara (TPS) karena berpotensi sebagai tempat pengolahan sampah organik rumah tangga ramah lingkungan. Pada akhirnya beberapa warga berinisiatif membuat sebuah komunitas peduli lingkungan yang berkonsentrasi pada pengolahan sampah organik rumah tangga menggunakan metode biokonversi. Biokonversi sampah yang dilakukan oleh 
Komunitas Peduli Lingkungan Villa Pisma Asri (KOPEL VIPA) di lingkungan RT 06 RW 05 Perumahan Villa Pisma Asri Kabupaten Pekalongan dengan jumlah mukim sebanyak 66 rumah tangga tersebut baru sebatas komunitas yang beranggota mukim sejumlah 5 rumah tangga, sehingga perlu dikembangkan dengan mensasar warga yang belum menjadi anggota komunitas dan berupaya untuk mendapatkan dukungan baik tingkat RT maupun tingkat RW.

Potensi strategis yang dimiliki warga di lingkungan RT 06 RW 05 dalam menjalankan aktifitas kelola sampah berupa fasilitas umum Tempat Penampungan Sementara (TPS) yang terbengkalai dan Ruang Terbuka Hijau (RTH) yang belum dimanfaatkan secara optimal oleh warga.

Fasilitas umum tersebut dapat digunakan sebagai wahana penunjang untuk mengedukasi warga dalam mengelola sampah organik rumah tangga dan menciptakan kemandirian pangan dengan memanfaatkan hasil olahan sampah berupa pupuk untuk sayuran organik dan prapupa lalat tentara hitam sebagai bahan substitusi pakan ternak berprotein tinggi.

Warga mukim di Perumahan Villa Pisma Asri Kabupaten Pekalongan, sebagaian besar merupakan keluarga kecil pada usia produktif. Dimana memerlukan dukungan dalam kemandirian pangan terutama untuk menambah kecukupan gizi pada ibu dan anak. Sehingga program biokonversi sampah organik rumah tangga tidak hanya sekedar aktifitas mengolah namun mempunyai arti penting dalam menyelesaikan masalah lingkungan, meningkatkan derajat kesehatan dan mendukung kesejahteraan keluarga.

\section{METODE}

Metode yang digunakandalam kegiatankemitraan ini meliputi pendekatan mitra, koordinasi mitra, sosialisasi pilah sampah dengan metode ceramah tanya jawab, pelatihan denganmetode small discussion dan demostrasi, aplikasi praktik pilah sampah dalam rumah tangga, pembuatan instalasi biokonversi dan pembuatan lahan aplikasi di ruang terbuka hijau (RTH) milik Perumahan Villa Pisma Asri berupa urban farming dan kolam ikan dengan sistem bioflok.

Tim mempersiapkan segala peralatan yang di butuhkan seperti infokus, lcd dan peralatan alat tulis maupun angket pada saat pelaksanaan sosialisasi pilah sampah, sedangkan pada saat pelatihan pemanfaatan sampah organic rumah tangga tim mempersiapkan alat-alat pembuatan tong bio reactor, larva lalat tentara hidap, sampah organic dan anorganik, peralatan pertanian lainnya. Pada pembuatan urban farming dan kolam bioflok sebagai lahan aplikasi hasil samping pengolahan sampah organic rumah tangga dengan metode biokonversi lalat tentara hitam tim menyediakan, gerobak soraong, alat pertanian dan pertukangan, kolam ikan dengan diameter 2 metar, bibit ikan, bibit tanaman, paranet, pipa vertikultur, polybag, serta alat dan bahan lain dalam pembuatan green hause yang di gunakan sebagai pangkalan tempat perkembang biakan lalat tentara hitam.

\section{HASIL DAN PEMBAHASAN}

1. Sosialisasi dan pendekatan mitra

Sosialisasi pilahsampah dilakukan sebanyak dua kali dengan maksuk agar lebih efektif penyampaian pada kelompok kecil. Tahap I dilakukan pada warga jalan sapier. Sasaran 95\% hadir dan aktif bertanya. $80 \%$ diantaranya menyatakan kesediaan ikut berperan aktif dalam PKM. Sosialisasi Tahap II dengan sasaran semua Warga Jl Giok Perumahan Villa Pisma Asri . Hasilnya $90 \%$ sasaran hadir dan antusias bertanya. $80 \%$ menyatakan kesediaan mengikuti program PKM

\section{Pelatihan Pengolahan sampah organic rumah tangga berbasis biokonfersi lalat tentara hitam}

Pelatihan pengolahan sampah organik rumah tangga menggunakan metode biokonversi yang memanfaatkan fase larva lalat tentara hitam dilakukan dengan melihat demonstrasi plot area yang dimiliki oleh Komunitas Peduli Lingkungan Villa Pisma Asri (KOPEL VIPA). Pelatihan dilakukan secara bertahap sebanyak tiga tahapan pada kelompok kecil masing-masing 22 kepala keluarga dengan mempertimbangkan kapasitas

$$
\text { Kesehatan } 446
$$


efektifitas demonstrasi plot area yang dimiliki oleh komunitas. Pelatihan dilakukan setiap akhir pekan dengan memanfaatkan waktu libur warga. Dalam pelatihan tersebut peserta mendapatkan edukasi tentang pilah sampah, penempatan sampah organik , perawatan larva lalat tentara hitam pada unit biokonversi berupa bioreaktor sampah organik , pemeliharaan prapupa, metode panen pupa, pengembangbiakan lalat tentara hitam, pengolahan residu sampah berupa pupuk organik dan pengolahan pupa lalat tentara hitam sebagai bahan substitusi pakan ternak.

\section{Instalasi biokonversi pada rumah tangga}

Pembuatan instalasi pengolahan sampah organik rumah tangga menggunakan metode biokonversi didampingi oleh Komunitas Peduli Lingkungan Villa Pisma Asri (KOPEL VIPA) untuk dipergunakan oleh warga di lingkungan RT 06 RW 05 Perumahan Villa Pisma Asri Kabupaten Pekalongan yang telah mengikuti pelatihan sebagai sarana pengolahan sampah organik rumah tangga. Pembuatan instalasi dilakukan dengan tahapan sebagai berikut:

a. Pembuatan Bioreaktor Larva

Pembuatan bioreaktor larva berfungsi sebagai sarana pemeliharaan larva lalat tentara hitam sebagai dekomposer. Bioreaktor berupa tabung yang berfungsi mengubah sampah organik rumah tangga menjadi produk lain yang berguna dan memiliki nilai tambah dengan memafaatkan proses biologis dari mikroorganisme dan enzim, produk yang dimaksud berupa pupuk organik. Dalam pembuatan unit biorekator dibutuhkan wadah berupa ember/drum berbahan plastic yang telah dimodifikasi sedemikian rupa sehingga dapat mendukung kehidupan larva lalat tentara hitam sebagai agen biokonversi selama siklus hidup 14 hari. Bioreaktor dibuat sebanyak 66 buah dengan masing-masing unit dapat menampung 1 kilogram larva lalat tentara hitam dan 14 kilogram sampah organik rumah tangga.

b. Pembuatan Kontainer Prapupa.

Kontainer prapupa berupa wadah plastic yang ditempatkan pada rak bertingkat berbahan besi dengan ukuran 40 x $180 \mathrm{x}$ $120 \mathrm{~cm}$. Rak bertingkat tersebut digunakan untuk menempatkan prapupa lalat tentara hitam yang berasal dari bioreaktor larva pada siklus hidup hari ke-15. Prapupa ditampung dalam container prapupa sampai berubah menjadi pupa sampai hari ke-33, sebagian dimanfaatkan sebagai indukan lalat tentara hitam dan sebagian lagi digunakan sebagai bahan substitusi pakan ternak yang dapat dimanfaatkan oleh warga menjadi pakan ikan, ayam, bebek maupun sublemen burung kicauan dengan nilai nutrisi yang tinggi.

c. Pembuatan Kontainer Pupa

Kontainer pupa berupa wadah plastic yang ditempatkan pada rak bertingkat berbahan besi dengan ukuran 40 x 180 x $120 \mathrm{~cm}$ kemudian ditutup menggunakan tirai jarring. Unit kontainer pupa dipergunakan sebagai tempat penampungan pupa sampai hari ke-33.

d. Pembuatan Kandang Perkembangbiakan Lalat Tentara Hitam

Kandang perkembangbiakan lalat tentara hitam dibuat dari kontainer plastik yang berfungsi sebagai tempat sementara perubahan pupa menjadi lalat dewasa. Unit tersebut terdiri dari container plastic yang disusun pada rak bertingkat dengan bahan besi yang ditutup dengan jarring dan dilengkapi wadah tempat telur indukan lalat tentara hitam.

\section{Aplikasi pilah sampah di Ruamah} Tangga

Aplikasi pilah dan olah sampah biokonversi sampah organik rumah tangga memanfaatkan larva lalat tentara hitam sebagai dekomposer, tahapan 
pengoperasian instalasi biokonversi sebagai berikut:

a. Sampah organik berupa sampah dapur (sisa makanan, sayur dan buah) dimasukkan dalam unit bioreaktor larva yang ditempatkan pada halaman rumah masingmasing warga yang telah mengikuti pelatihan. Kapasitas pengolahan setiap hari sebanyak 1 kilogram sampah organik rumah tangga dengan kandungan air $70 \%$ akan diuraikan oleh 10.000 larva lalat tentara hitam dan menyisakan sekitar 200 gram sampah terurai. Proses biokonversi mensyaratkan kandungan air dalam sampah organik rumah tangga tidak lebih dari kisaran $70 \%$ untuk menghindari terjadinya proses dekomposisi basah yang dapat berisiko menghasilkan polusi udara (bau) dan memudahkan dalam proses panen. Bioreaktor larva dapat bekerja secara optimal lebih kurang selama 14 hari menyesuaikan siklus hidup lalat tentara hitam pada fase larva.

b. Metamorfisis dalam siklus hidup lalat tentara hitam mengharuskan tersedia unit pemeliharaan secara berkelanjutan, larva merubah menjadi prapupa pada hari ke-15 sehingga diperlukan proses pemindahan larva beserta media pemeliharaan dari bioreaktor larva kedalam container prapupa sampai hari ke-21.

c. Pada hari ke-22 dilakukan pemindahan prapupa lalat tentara hitam ke dalam kandang perkembangbiakan yang terdiri dari container pupa yang disusun pada rak bertingkat berbahan besi dan ditutup tirai jarring, pupa berada dalam container pupa untuk melengkapi siklus berikutnya sampai hari ke-33 menunggu berubah menjadi lalat tentara hitam dewasa.

d. Lalat tentara hitam dewasa yang dipelihara dalam jarring perkembangbiakan akan menghasilkan telur yang dapat ditetaskan menjadi larva pada hari ke-42. e. Telur lalat tentara hitam memerlukan masa inkubasi selama 3 hari untuk menetas, larva yang menetas pada hari ke-45 dapat dimasukkan kedalam unit bioreaktor larva sebagai agen biokonversi sampah organik rumah tangga yang ditempatkan pada halaman rumah masing-masing warga di lingkungan RT 06 RW 05 Perumahan Villa Pisma Asri Kabupaten Pekalongan.

\section{Aplikasi Hasil samping dari Biokonversi sampah Rumah Tangga di Uraban Farming}

Tahap Aplikasi hasil samping pengolahan sampah dengan sistem biokonversi sampah organic rumah tangga dilakukan untuk melakukan manajemen hasil panen Ikan dan sayuran hijau yang di hasilkan dalam proses pengelolaan dan pemanfaatan hasil pengolahan sampah. Panen ikan dapat dilaksanakan dalam dua bulan sekali. Sebagian hasil panen di bagikan ke warga dan sebagian di jual guna pembelian bibit lele lagi. Sedangkan panen sayuran dapat dipanen setu bulan sekali dan dibagikan ke warga dengan estimasi setengah kilogram per kepala keluarga.

\section{Evaluasi Kegiatan}

Evaluasi proses pelaksanaan PKM dilakukan bersama dengan warga dan ketua RT maupun Ketua RW dengan menampilkan berubahan analisa situasi setelah dilakukan PKM. Tindak Lanjut pelaksanaan PKM dilakukan pengorganisasian pada warga dapat ditindaklanjuti kegiatan PKM secara mandiri. Ketua RW didatangkan dengan harapan dapat menyetujui dan sebagai upaya pendekatan agar RT lain dapat melakukan pemanfaatan dan pengolahan sampah serupa dengan RT06 RW05 dan menginisiasi usaha mikro di RT maupun RW dengan budidaya sayur organik dan budidaya ikan. 


\section{KESIMPULAN}

Rangkaian kegiatan program kemitraan masyarakat meliputi sosialisasi berupa edukasi dan pembuatan tentang perilaku pilah sampah, pelatihan teknik pengolahan sampah organik rumah tangga menggunakan metode biokonversi dan pemanfaatan produk samping pengolahan sampah, pembuatan instalasi pengolahan sampah organik rumah tangga di lingkungan RT 06 RW 05 Perumahan Villa Pisma Asri Kabupaten Pekalongan dengan memanfaatkan fasilitas umum Tempat Penampungan Sementara (TPS) dan Ruang Terbuka Hijau (RTH), pengoperasionalkan instalasi pengolahan sampah organik rumah tangga oleh warga RT 06 RW 05 Perumahan Villa Pisma Asri Kabupaten Pekalongan sebagai pelaku dan penyedia sampah, dan pemanfaatan produk samping pengolahan sampah organik rumah tangga berupa pupuk organik. Seluruh komponen warga dan perangkat desa Podo Kecamatan Kedungwuni mendukung pelaksanaan kegiatan ini

\section{UCAPAN TERIMAKASIH (Bila ada)}

Terima kasih disampaikan kepada Kementerian Riset, Teknologi, dan Pendidikan Tinggi Republik Indonesia yang telah mendanai Program Kemitraan Masyarakat melalui Hibah PKM tahun pelaksanaan 2019, Lembaga Penelitian dan Pengabdian Masyarakat Universitas Muhammadiyah Pekajangan Pekalongan dan Desa Podo Kecamatan Kedungwuni yang telah menfasilitasi proses kegiatan pengabdian ini sampai akhir..

\section{REFERENSI}

(KLHK) Kementrian Lingkungan Hidup dan Kehutanan. 2015. Rangkaian hari lingkungan hidup 2015-dialog pengolahan sampah plastic (Internet)(diunduh 2 September 2019).

Balitbangtan (BB Veteriner). Maret 2016. Lalat Tentara Hitam Agen Biokonversi Sampah Organik Berprotein Tinggi. Diakses dari : http://www.litbang.pertanian.go.id/berita/ one/2557/ (10 Juni 2016)

Dortmans B.M.A., Diener S., Verstappen B.M. Zurbrug C. 2017. Black Solder Fly
Biowaste Processing-A Step-by-step Guide.Eawag : Swiss Federal Institute of Aquatic Science and Tecnology, Dubendorf, Switzerland.

Fahmi, M. R. (2015). Optimalisasi proses biokonversi dengan menggunakan minilarva Hermetia illucens untuk memenuhi kebutuhan pakan ikan. Pros sem nas masy biodiv indon, 1(1), 139-144.

Furnanda,Riska. 2012. Partisipasi Ibu Rumah Tangga dalam Mewujudkan Program Medan Green n Clean (MdGC) Melalui Pengelolaan Bank Sampah di Lingkungan II Kelurahan Tanjung Gusta Kecamatan Medan Helvetia Kota Medan. Skripsi. Fakultas Kesehatan Masyarakat. Universitas Sumatera Utara.

Kementrian Hukum dan Hak Asasi Manusia RI. 2008. Undang-Undang Republik Indonesia Nomor 18 Tahun 2008 tentang Pengelolaan Sampah.

Notoatmodjo, S. 2003. Pendidikan Dan Perilaku Kesehatan. Jakarta: PT. Rineka Cipta.

Nurhidayat, Setyo Purwendro, 2010. Mengolah sampah untuk Pupuk dan Pestisida Organik. Penebar Swadaya Jakarta.

Pemerintah Daerah Kabupaten Pekalongan. 2017. Peraturan Daerah Kabupaten Pekalongan Nomor 4 Tahun 2017 tentang Pengelolaan Sampah. Pekalongan : Pemerintah Kabupaten Pekalongan

Suciati, R. (2017). Efektifitas Media Pertumbuhan Maggots Hermetia Illucens (Lalat Tentara Hitam) Sebagai Solusi Pemanfaatan Sampah Organik. Biosfer: Jurnal Biologi Dan Pendidikan Biologi, 2(1), 8-13. 